Luca Bullaro*

\title{
Sabias integraciones tropicales. \\ Concatenación arte-técnica-paisaje en la modernidad de Niemeyer, Burle Marx y Cardoso ${ }^{1}$
}

\author{
Tropical links. Wise connections between arts, \\ technology and landscape in the work of Niemeyer, \\ Burle Marx and Cardoso
}

\section{Cómo citar:}

Bullaro, L. (2017). Sabias integraciones tropicales. Concatenación arte-técnica-paisaje en la modernidad de Niemeyer, Burle Marx y Cardoso. Designia, 4(2), 9-35.

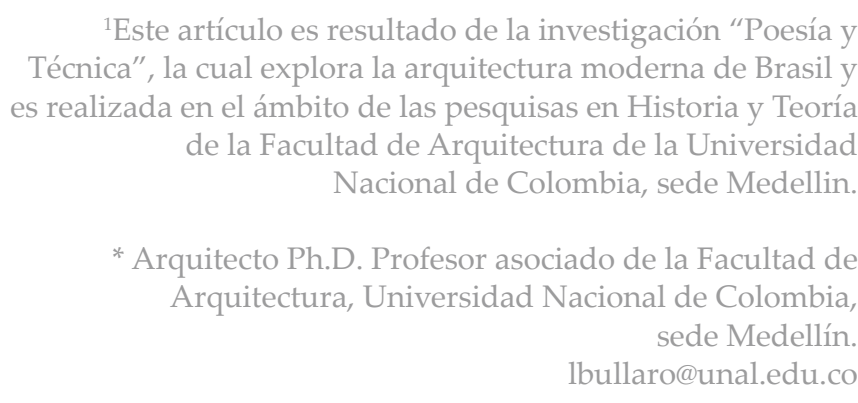

Palabras clave:

Movimiento Moderno, arquitectura tropical, Oscar Niemeyer, Roberto

Burle Marx, Joaquim Cardoso.

Key words:

Modern Movement,

tropical architecture, Oscar

Niemeyer, Roberto Burle Marx,

Joaquim Cardoso.

Recibido: 27/04/2016

Aceptado: 19/09/2016

\section{Resumen:}

Este artículo analiza tres obras modélicas de la arquitectura moderna de Brasil y quiere demostrar que la sobresaliente calidad de tales ensayos procede de la inteligente concatenación entre paisaje, estructura y arte. Estos diseños integrales y orgánicos se generaron gracias a la creación de grupos multidisciplinarios cuyos miembros siguieron pautas conceptuales y morfológicas precisas, derivadas de la fusión de las enseñanzas del 
Movimiento Moderno europeo con el estudio de las características geográficas y climáticas del mundo tropical de América Latina. En términos metodológicos, el trabajo aquí presentado alternó fases de consulta bibliográfica con visitas a las obras y análisis de tipo climático y paisajístico. De tal modo, se reconstruyeron pautas estratégicas de los grupos a partir del estudio de la Casa Canavelas, la Casa das Canoas y la Iglesia de São Francisco de Assis. Se trata de proyectos surgidos en contextos diferentes, desarrollados en ambientes extraurbanos y en contacto directo con la vegetación de Brasil. El arquitecto Oscar Niemeyer aparece como coordinador y facilitador del trabajo conjunto de artistas, ingenieros, paisajistas y botánicos (entre quienes se destacan Portinari, Burle Marx y Cardoso) para realizar propuestas integrales en continuidad armónica con el ambiente. Una sabia metodología, factible de ser reinterpretada en proyectos paisajísticos contemporáneos que se integren de forma orgánica al entorno natural.

\section{Abstract:}

This paper analyses exemplary works of modern architecture in Brazil, aiming to demonstrate that their remarkable quality comes from a clever combination between landscape, structure and art. Such comprehensive designs were conceived by multidisciplinary groups whose members followed very precise conceptual and morphological patterns derived from the fusion of the European Modernism and the study of the geographical and climatic characteristics of the tropical world. In this paper three holistic creations are analysed after visiting them, reviewing literature related to them and surveying their contexts. Such paradigmatic cases are Casa Canavelas, Casa das Canoas and São Francisco de Assis Church, which are located in extra-urban environments, in contact with the extraordinary vegetation of Brazil. They evidence how the new spatiality is the result of merging architectural, natural and structural elements with common morphological rules over the distinct aspects of design. Architect Oscar Niemeyer appears as a coordinator who facilitates the joint work of artists, engineers, landscapers and botanists (Portinari, Burle Marx and Cardoso excel among them) in order to carry out complex proposals in harmonious continuity with the context. A wise methodology for being reinterpreted in contemporary landscape projects that respect and integrate the natural environment. 


\section{INTRODUCCIÓN}

A partir de los años treinta del siglo pasado, representantes de la nueva arquitectura en Brasil comenzaron a incorporar conceptos del Movimiento Moderno, si bien, como escribe el arquitecto e historiador italiano Alberto Sartoris (2005), no los aplicaron de manera directa: los reinterpretaron, tradujeron y adaptaron a las condiciones climáticas y paisajísticas del país.

En este artículo se describe la apropiación de algunas de esas teorías, como también sus sabias transformaciones. Para tal fin se analizan tres proyectos modélicos con una notable concatenación entre espacialidad, arte, paisajismo y técnica estructural: la Casa Canavelas, la Casa das Canoas y la Iglesia de San Francisco de Asís, obras holísticas que demuestran la fusión de elementos arquitectónicos, naturales y estructurales a partir del uso de reglas morfológicas análogas en los diferentes aspectos del proyecto.

Uno de los artífices de esa revolución arquitectónica fue Lucio Costa. Consciente de la importancia de los principios de la Modernidad, de la difusión de una nueva didáctica y de la calidad del trabajo de los grupos multidisciplinarios, supo formar intelectuales de nivel sobresaliente, quienes trabajaron bajo los preceptos de Le Corbusier en el proyecto de la nueva sede del Ministerio de Educación y Salud en Rio de Janeiro, ejemplo contundente de la concatenación entre arquitectura, espacio público, artes, estructura, paisajismo y mobiliario (Le Corbusier, 1995).

Bruno Zevi (1982) afirma que el protagonista de la revolución fue Roberto Burle Marx, artista del paisaje, botánico, escritor y pintor. A su vez, Kenneth Frampton (2009) e Iñaki Abalos (2009) ponen en evidencia la extraordinaria creatividad del joven Oscar Niemeyer. Aun así, la relevancia de la arquitectura moderna brasileña, según William Curtis (2012), no reside tanto en las notables capacidades de unos pocos, sino en la asimilación de un método de trabajo que dio protagonismo al diálogo entre maestros de diversos saberes.

Burle Marx fue de los primeros y principales paisajistas en proponer la creación de espacios públicos modernos, realizados mediante la utilización de diferentes elementos naturales, formas, colores y texturas, todo típico del país (Siqueira, 2001). Niemeyer, por su parte, influenciado por las ideas del amigo botánico, emprendió al final de los años treinta obras novedosas, sensuales y orgánicas. Además de las tres aquí analizadas, cabe destacar el Pabellón de New York (con Lucio Costa), la Casa do Baile, el Parque Ibirapueira y la Catedral de Brasilia, todas en colaboración con Burle Marx, Joaquim Cardoso y varios amigos artistas. 
Promotores de los resultados del Brasil moderno fueron, entre otros, Cardoso (ingeniero y hombre de letras) y los artistas Bruno Giorgi, José Sarney, Paulo Werneck, Candido Portinari, Marianne Peretti, Athos Bulcão, y Alfredo Ceschiatti. Cabe destacar también el valioso rol de políticos progresistas como Gustavo Capanema, fundamental para el fomento de la integración entre las artes.

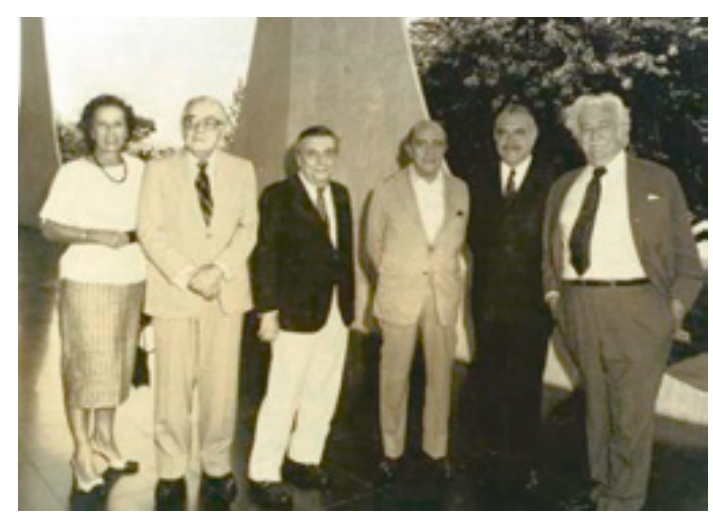

Figura 1. Los artistas Marianne Peretti, Athos Bulcão, Alfredo Ceschiatti, Oscar Niemeyer, José Sarney y Burle Marx en Brasilia. Fuente: Archivo Aló, Rio de Janeiro.

\section{METODOLOGÍA}

La investigación se centró en dos apartados metodológicos, uno teórico y otro práctico. Asimismo, se fundó en el acercamiento a las condiciones climáticas y paisajísticas de algunas zonas rurales de Brasil, con el fin de comprender cómo se enraizaron en este ambiente varios ensayos espaciales modernos. Se desarrolló una aproximación conceptual y física a obras de Niemeyer y Burle Marx, por medio de visitas, reportajes fotográficos, diálogos con colaboradores cercanos y estudiosos que se han ocupado de la poética de los maestros. Igualmente, se recopilaron distintas interpretaciones de esos proyectos, elaboradas por historiadores, críticos y arquitectos de renombre internacional. 
Se analizaron las razones conceptuales, estructurales y morfológicas de las obras modélicas y se escogieron aquellas emplazadas en ambientes extra-urbanos, en contacto con la extraordinaria vegetación tropical. También se desarrolló una fase analítica y comparativa desde los puntos de vista arquitectónico y paisajístico, mediante un estudio del entorno. De este modo se buscó demostrar que ciertas características del paisaje autóctono guiaron la génesis conceptual y estética de los proyectos.

\section{TRES OBRAS INTEGRALES}

Para resaltar determinadas características de la metodología de los grupos multidisciplinarios de trabajo y discutir algunos de sus temas cardinales, se describen tres obras paradigmáticas (dos residencias privadas y un edificio para el culto católico) que representan bien la estrategia de compartir saberes y propósitos en consonancia con un fin armónico, plástico y funcional.

En la Casa Canavelas la colaboración entre Niemeyer y Burle Marx produjo una obra insertada en el exuberante entorno, con discreción y contundencia al mismo tiempo: una bisagra artificial en forma de puente que conecta visualmente las dos laderas del valle y permite apreciar desde un punto de vista privilegiado la perfección de los dos jardines, uno "geométrico" y otro "orgánico".

En la Casa das Canoas, la cubierta configura un abrazo arquitectónico-conceptualmente similar a la Piazza San Pietro de Gian Lorenzo Bernini- que acoge la piedra-altar. La naturaleza se engloba a la arquitectura generando un sistema de espacios que reinterpreta las reglas biológicas y geológicas de las montañas cercanas y da vida a una creación holística.

En la Iglesia de Pampulha (San Francisco de Asís), arquitecto, artista, ingeniero y paisajista (Niemeyer, Portinari, Cardoso y Burle Marx) operan juntos para lograr una novedosa espacialidad a partir de la articulación de elementos provenientes de universos distintos, con el sabio empleo de cánones morfológicos similares. 
El estudio de estos tres proyectos puso de manifiesto el rol del arquitecto: inteligente coordinador de un grupo multidisciplinario integrado por artistas, expertos en estructuras, paisajistas y botánicos, que se encargó de realizar un sistema orgánico de oasis enraizado con sutileza en el entorno geomorfológico.

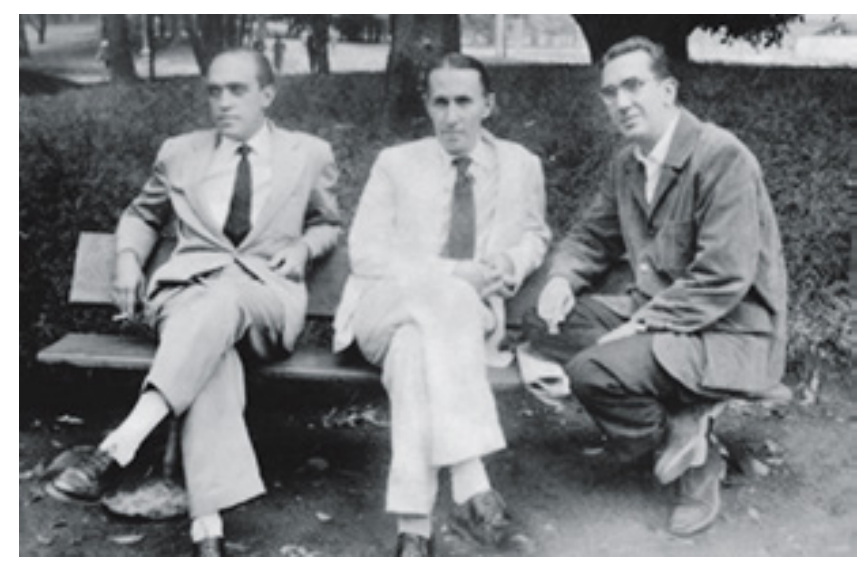

Figura 2. Oscar Niemeyer, Joaquim Cardoso y Paulo Werneck en Pampulha (1944). Fuente: Archivo Globo. Disponible en: http://casavogue.globo.com/MostrasExpos/ Arte/noticia/2015/01/arte-publica-de-paulo-werneck.html

\section{LA CASA CANAVELAS Y SU CONEXIÓN PAISAJÍSTICA}

La casa, construida en 1954 en la zona de Pedro do Rio, a pocos kilómetros de Rio de Janeiro, es uno de los proyectos más humildes de Niemeyer, perfectamente enraizado en el paisaje circundante. La cubierta actúa como una conexión visual, en forma de catenaria, entre las dos laderas de las colinas adyacentes. La arquitectura, implantada en la parte baja del valle, se acomoda al sitio y origina un poético controcanto respeto al poderoso sistema natural. 


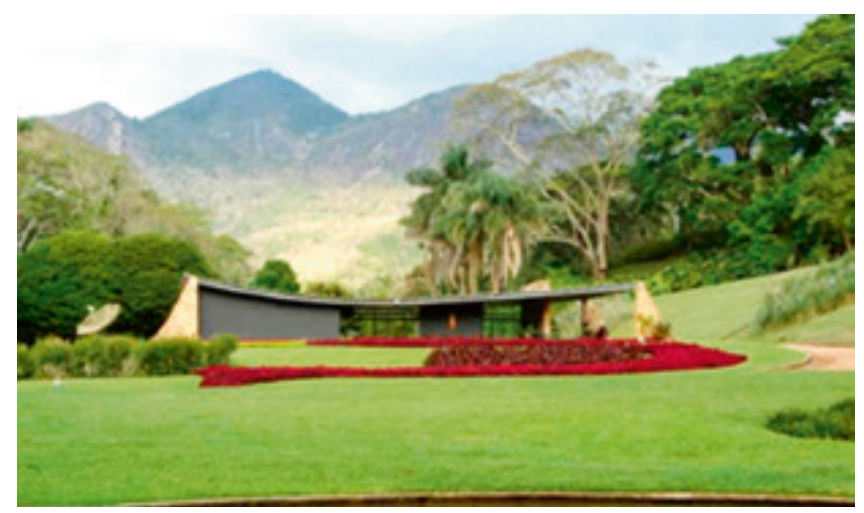

Figura 3. Casa Canavelas: la arquitectura y el paisajismo reinterpretan las reglas biológicas y geológicas del entorno.

Fuente: Archivo Leonardo Finotti. Disponible en http://leonardofinotti.com

Al analizar los elementos arquitectónicos intrínsecos se puede afirmar que el proyecto reinterpreta algunos cánones conceptuales y estéticos del movimiento De Stijl. Si se observan, por ejemplo, los muros pétreos que se extienden hacia el paisaje, se perciben también influencias del Pabellón de Barcelona y del proyecto no realizado de la Casa de ladrillo de Mies Van Der Rohe.

Característica primordial de las obras De Stijl es la "disolución de la caja" (Zevi, 1997) y la configuración a partir de elementos bidimensionales. La Casa Canavelas obedece a estos criterios. Dos pantallas de piedra se erigen protagónicas: la primera acoge la chimenea, la segunda se prolonga hacia al paisaje para conectar visualmente la sala con el jardín. Las otras paredes son transparentes, tres en el salón y una en el área más íntima de las habitaciones.
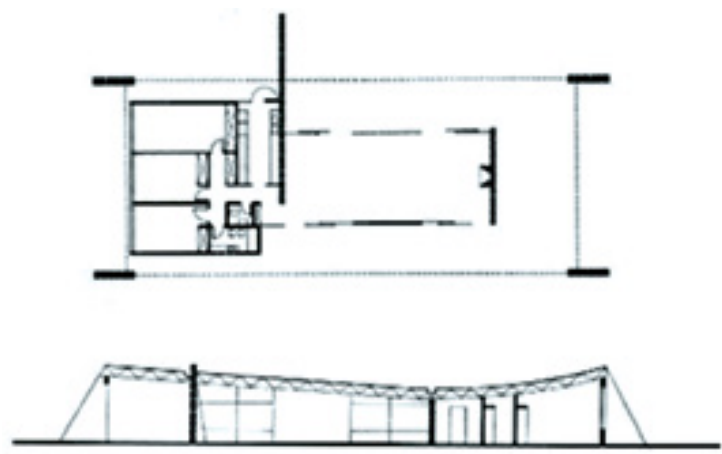

Figura 4. Casa Canavelas Planta y sección longitudinal. Fuente: Papadaki (1956). 
La cubierta define la imagen exterior: es el único componente curvo y se arquea para integrarse de forma delicada al paisaje adyacente. Es interesante observar la residencia desde un punto lejano, por ejemplo desde los límites extremos del jardín. Se percibe cómo la arquitectura se enraíza en el entorno y la cubierta sirve de conexión: es una cortina suspendida que configura un preciso vínculo morfológico con las laderas del valle. Al examinar los dibujos y croquis originales de Le Corbusier (Petit, 2014/1965) se podría conjeturar una reinterpretación por parte de Niemeyer de la morfología del intradós de la Capilla de Ronchamp.

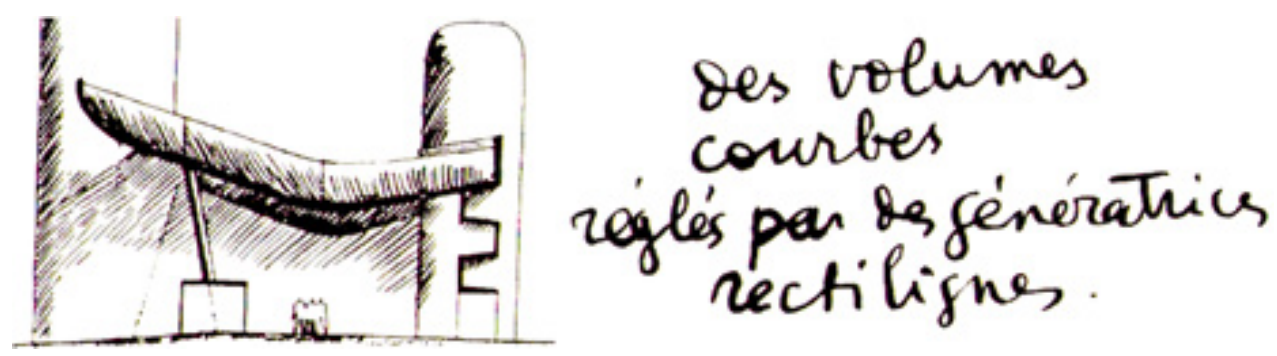

Figura 5. Detalles de páginas del libro Chapelle Notre Dame Du Haut, en el cual Le Corbusier escribe: "Volúmenes curvos organizados por generatrices rectilíneas". Una metodología similar se utilizó en el proyecto de la cubierta de la Casa Canavelas.

Fuente: Petit (2014).

La residencia es un llamativo ejemplo de adaptación al clima tropical de la zona. El arquitecto evita la colocación de extensas superficies vidriadas en correspondencia del perímetro de la cubierta y resuelve crear un espacio abierto de casi tres metros de ancho alrededor del salón con el fin de resguardar el interior de los rayos directos del sol y de las intensas lluvias. Económicas cerchas metálicas constituyen las catenarias sobre las cuales se apoya la cubierta. Una cámara de aire entre el extradós y el intradós protege del calor del trópico. 
En su planta, la casa es un rectángulo alargado, de proporciones áureas, dividido en dos partes, un rectángulo áureo y un cuadrado. El primero se abre hacia al eje longitudinal del sistema natural y acoge el salón, en tanto el segundo lo hace hacia una de las laderas y alberga los servicios y las habitaciones.

La poética de Burle Marx se fusiona de manera armónica y elegante con la de Niemeyer. El paisajista utiliza métodos distintos para las dos porciones del valle. Hacia el lado este desarrolla un jardín geométrico basado en la repetición de cuadrados que se despliegan a partir de la geometría de la planta de la vivienda y definen la morfología de la piscina. En la parte oeste incorpora algunos de los temas morfológicos típicos de su obra gráfica: un sistema de curvas y contracurvas conforma una ameba sinusoidal que une visualmente la sala principal con el conjunto natural y el estanque.

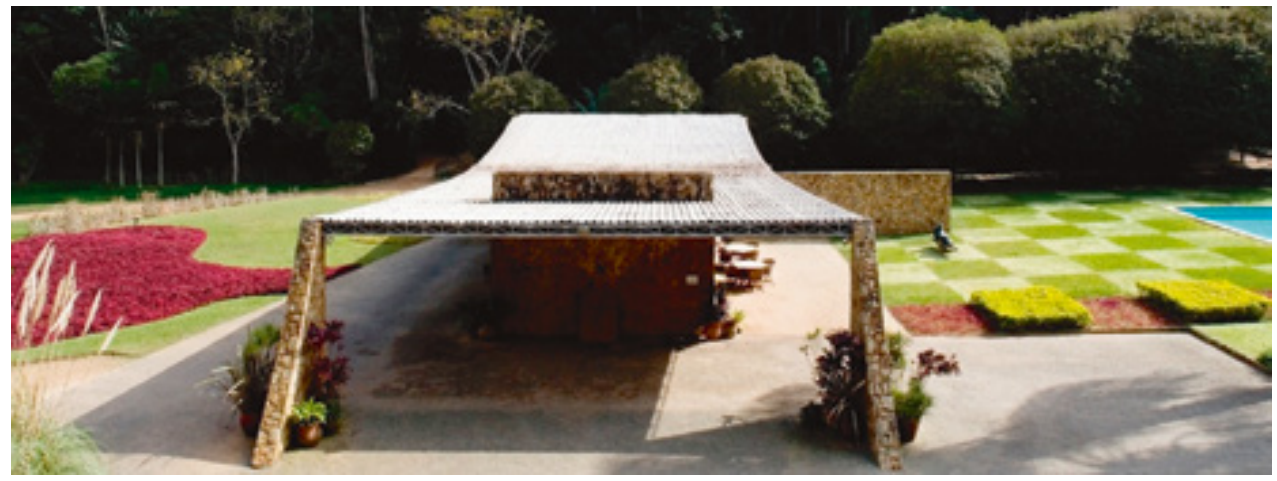

Figura 6. La Casa Canavelas y los jardines de Burle Marx. Fuente: Archivo Luca Bullaro. 
La escultura en bronce realizada por Alfredo Ceschiatti, ubicada entre la casa y el jardín, en correspondencia con el límite del muro pétreo, es un homenaje al paisaje de los alrededores de Río de Janeiro. Representa una mujer acostada con el brazo levantado cuyo perímetro recuerda las montañas cercanas.

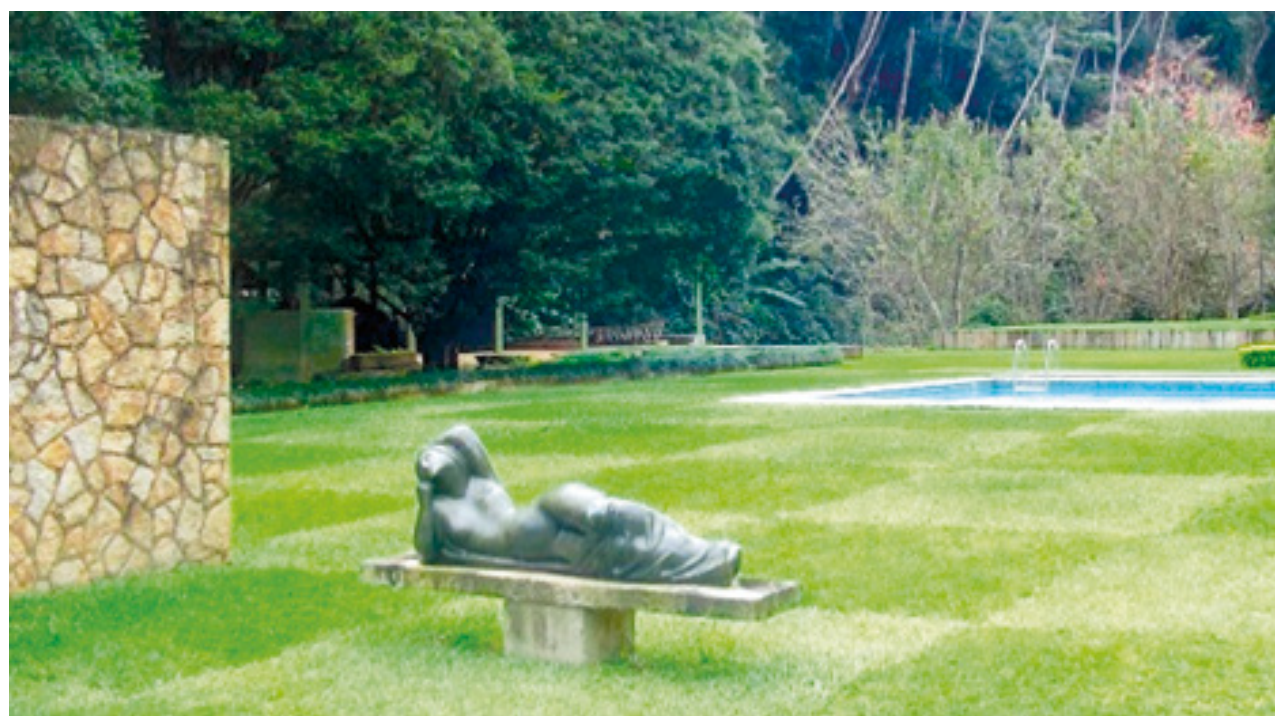

Figura 7. La escultura de Ceschiatti en relación con el jardín, la piscina y el muro pétreo.

Fuente: fotografía del autor.

De extraordinaria belleza y herramienta fundamental para el análisis de la obra es el reportaje fotográfico de Leonardo Finotti. Llama la atención la imagen tomada desde el salón, con vista hacia la piscina. Se aprecian las dos laderas encuadradas por los elementos arquitectónicos del muro pétreo, la cercha metálica de la cubierta y el pavimento exterior a base de pequeñas piezas en piedra con tonalidades de la tradición portuguesa. El rectángulo visual enmarca el sistema linear y pautado de los troncos de las altas palmeras, al igual que la geometría euclidiana del jardín, lograda a partir de los cuadrados repetidos de dos tipos de hierba de tonalidad diferente, y el plano azul de la piscina. 


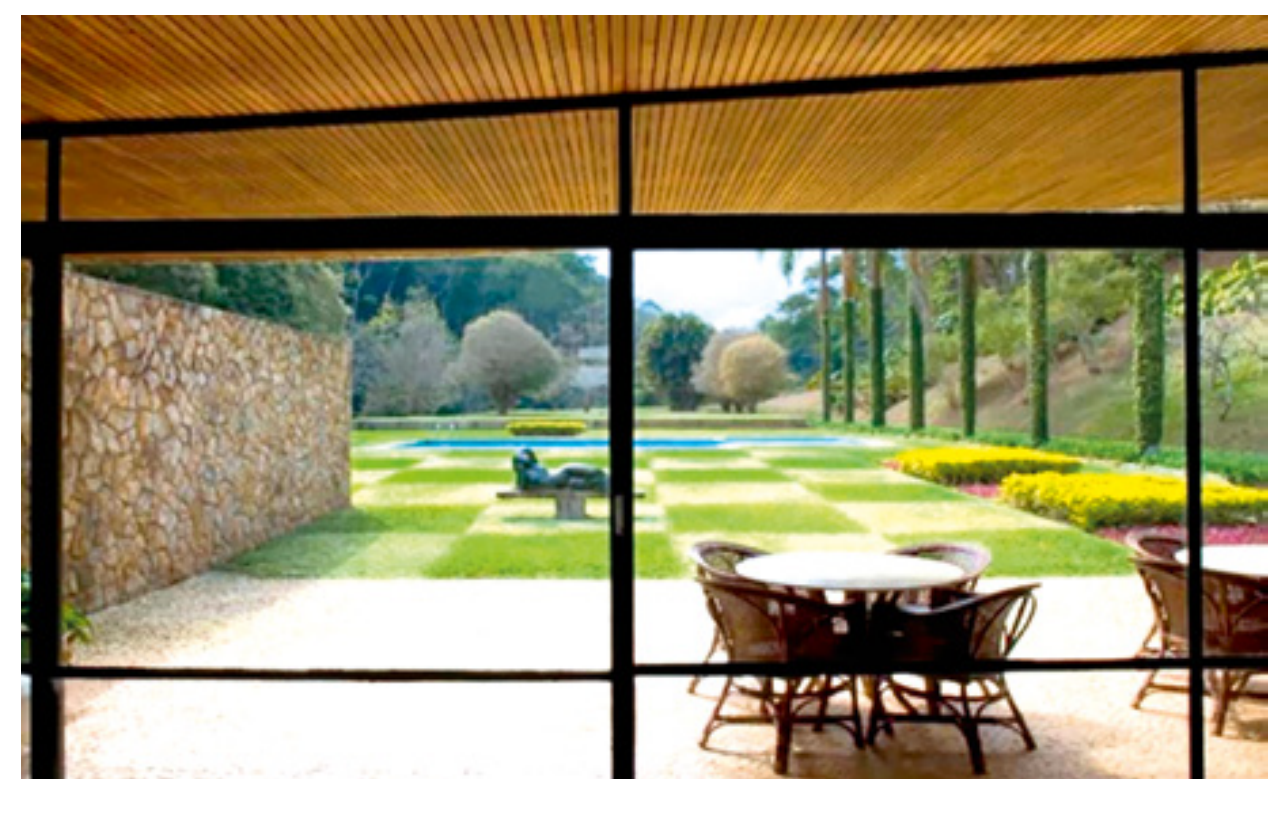

Figura 8. Relaciones visuales entre naturaleza y artificio desde el espacio abrigado. Fuente: Leonardo Finotti. Disponible en http://leonardofinotti.com

La ameba sinusoidal que caracteriza la otra franja del jardín y contrasta con la severidad de los componentes artificiales, parece representar los meandros de un río. Los mismos meandros de América Latina que tanto interés causaron, en términos formales y metafóricos, a Le Corbusier. Burle Marx los reinterpretó en forma de arte orgánico con elementos, colores y texturas naturales, en este caso, con el auxilio de plantas autóctonas de color morado.

El espacio interior define un diálogo cromático entre secciones claras como el pavimento y oscuras como el falso techo. También es notorio el delicado contraste en la superficie horizontal en piedra blanca (lisa en el interior y texturizada en las terrazas), conformada por pequeños objetos pétreos, típicos de la colonización portuguesa. El intradós de la cubierta se plasma con tablas de madera de tonalidad marrón, en tanto los dos muros pétreos del salón son ocres. La perfilaría del pan de verre es metálica, delgada y pintada de negro. Como señala Papadaki (1956), la casa es una estructura completamente abierta que ofrece una interferencia mínima con el paisaje de sus alrededores. Se transmite una idea de comunión entre arquitectura y entorno y se genera un sistema de enmarcación de este último, verdadero protagonista del conjunto. Todo basado en el posicionamiento de sencillos elementos artificiales, apoyados al valle con maestría, siguiendo pautas morfológicas similares o una geometría austera que crea el sutil contraste con las características del medio. 


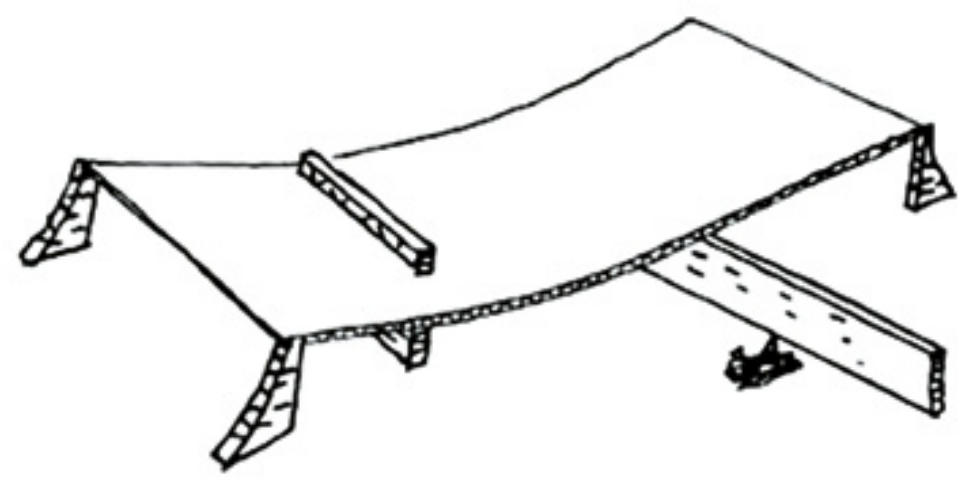

Figura 9. Oscar Niemeyer, croquis de los elementos básicos y estructurales de Casa Canavelas. Fuente: Papadaki (1956).

El análisis de los bocetos preliminares de Niemeyer, por ejemplo el esquema isométrico que representa con pocas líneas las pautas morfológicas y constructivas de la casa, proporciona reflexiones claves sobre la coherencia entre ideas conceptuales y tectónicas. El proyecto realizado, que se puede considerar una fiel materialización de la base teórica, consigue con mínimos medios y recursos una fina integración entre colores, texturas, formas, estructura y elementos naturales del entorno.

\section{INTEGRACIÓN ARTE-PAISAJE EN LA CASA DAS CANOAS}

Oriol Bohigas (2012) destaca que a partir de las enseñanzas de Le Corbusier, Niemeyer contribuyó a transformar la fisonomía de la arquitectura moderna al inventar fórmulas basadas en un lenguaje menos dogmático y en un realismo ambiental. Según William Curtis (2012) su arquitectura tenía un cariz progresista pero incluía lecciones del pasado y de la naturaleza. Muchas obras de Niemeyer, comenta también Curtis, pueden considerarse maestras, como es el caso de la Casa das Canoas, donde se mezclaron el rigor de la estructura moderna, la fluidez del espacio y la forma y la sensibilidad hacia lo natural. 
La Casa das Canoas se edificó en 1952 en la ladera de una colina cercana a São Gonzalo, a pocos kilómetros de Río de Janeiro. Hoy en día aparece como una intervención poética incorporada a la naturaleza con respeto y precisión. La obra se ajusta al clima cálido de la región y protege los lugares de estancia gracias a una extensa cubierta que vuela más allá del perímetro de las paredes. Las puertas-ventanas transparentes se abren al paisaje, la piscina parece hacer parte del salón, desde donde se aprecia una sinfonía compuesta por la vegetación, los pájaros y la quebrada que fluye al lado de la pared pétrea del nivel inferior. Niemeyer (1998, p. 174) comentó: "Me preocupaba diseñar la residencia con gran libertad, adaptándola al terreno irregular, asegurándome de que la vegetación podría penetrar dentro de sus curvas, sin la separación ostensiva de la línea recta". La idea básica reside en la construcción de una plataforma: un lugar tranquilo y seguro en medio de la naturaleza donde la cubierta en voladizo protege de la lluvia y del sol, en tanto un espejo de agua rememora morfológicamente y metafóricamente la Laguna Rodrigo de Freitas, en Ipanema.

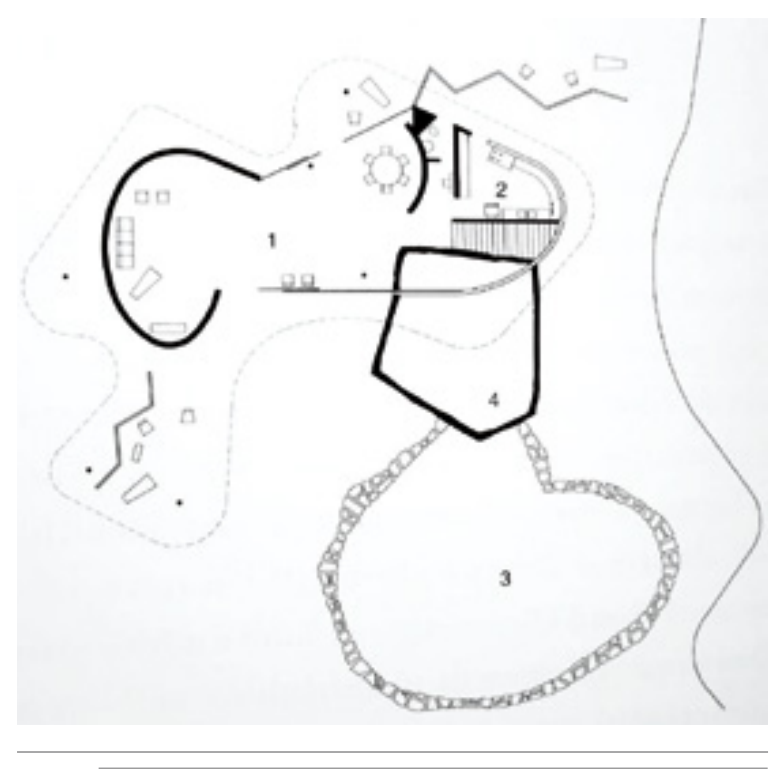

Figura 10. Casa das Canoas,

planta: 1. Salón, 2. Cocina, 3. Piscina, 4. Roca.

Fuente: Underwood (2010). 
Considerada un ejemplo significativo de la arquitectura moderna de Brasil por la originalidad de sus formas libres y la sensualidad del perímetro sinuoso de su cubierta, en escasas ocasiones se analizó para resaltar su valor conceptual, su relación con el arte y el paisaje, la forma perfecta como amoldó al ambiente circundante. La porción más íntima se esconde debajo del área social, en el basamento de piedra, y es estereotómica, oscura y con pequeñas ventanas. La zona más pública se abre hacia al paisaje y reinterpreta la fragmentación de la caja volumétrica de raíz neoplástica. Una despliega los espacios más privados para estudiar, escribir, dibujar y descansar, la otra se ofrece a la vida social.

Los aleros generosos de la cubierta buscan proteger el espacio y configurar lugares de estancia al aire libre, frescos y abrigados. En este elemento protagónico es clara la referencia a la arquitectura vernácula tropical y colonial, mencionada por Niemeyer en entrevistas y en sus escritos.

Al visitar la casa, el sonido natural motiva múltiples sensaciones poéticas. Antes de llegar a la plataforma central se cruza un pequeño arroyo, aprovechado por Niemeyer para organizar un camino teatral donde se fusiona arte, arquitectura y naturaleza con la génesis de un puente que da la bienvenida, gracias al canto de pequeñas cascadas, y conduce a la piscina central. Los colores subrayan las sinuosas curvas arquitectónicas: blanco en la superficie de la cubierta y azul en el agua, los cuales dialogan, a su vez, con sus pares en las nubes y el cielo, respectivamente. El gris está en la piedra y el verde en algunos muros curvos, además de ser el protagonista absoluto de la vista lejana. Desde el interior se disfrutan dos paisajes: uno cercano y artificial, realizado gracias a la colaboración de Burle Marx, casi una maqueta de la laguna de Ipanema y del Pão de Açúcar; el otro distante, dominado por los altos árboles y las montañas. A finales de los años cincuenta el maestro finlandés Alvar Aalto (2000) reflexionó poéticamente:

\footnotetext{
En una conversación que mantuve con Lucio Costa sobre Brasil, comenzamos a hablar de la clase de flores que no pueden trasplantarse y que son bellas y apropiadas únicamente en su propio hábitat. La casa de Oscar Niemeyer es ese tipo de flor. Hay que verla donde está, en su valle reverdecido. No es posible fotografiarla, ya que su forma multidimensional exige un arte que capte al mismo tiempo tanto todo el valle como el interior y el exterior de la casa. Es una flor exquisita que crece en un medio encantado (p. 198).
} 


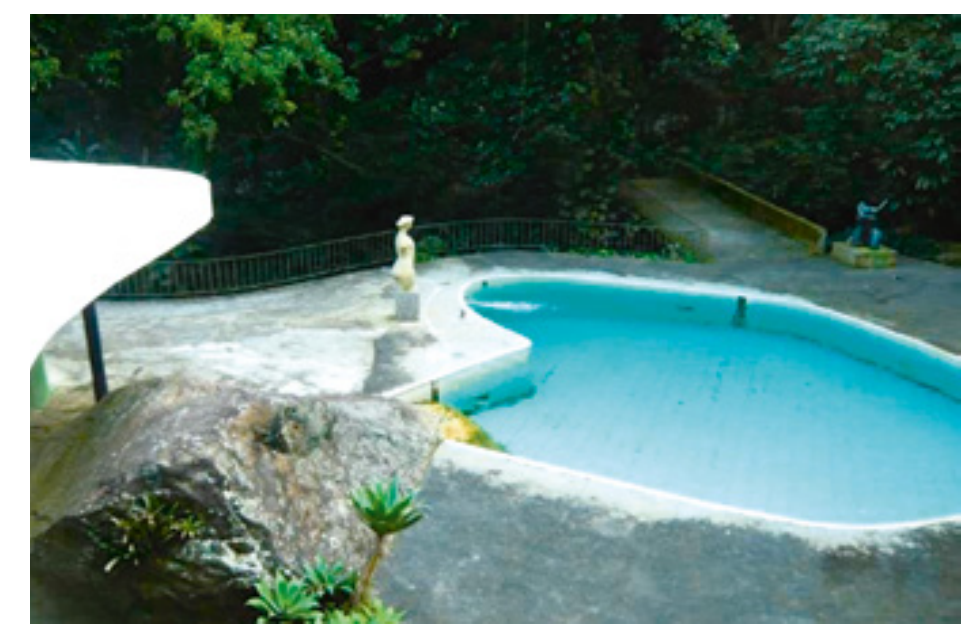

Figura 11. Casa das Canoas. Vista desde la cubierta. Fuente: fotografía del autor.

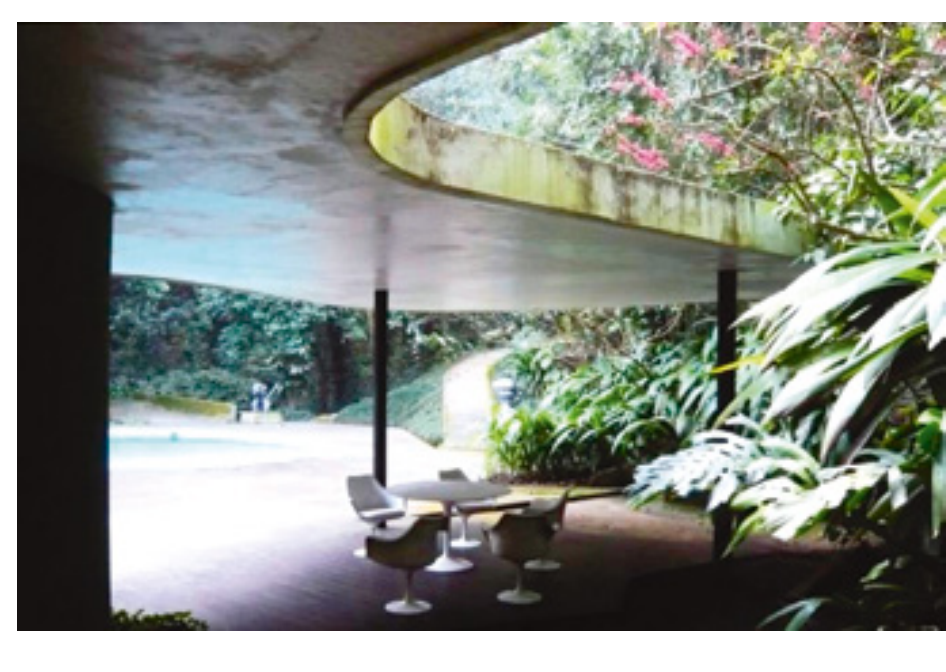

Figura 12. Casa das canoas. Compenetración entre elementos naturales y artificiales. Fuente: fotografía del autor. 


\section{FUSIÓN DE ARTE Y TÉCNICA EN LA IGLESIA SAN FRANCISCO DE ASÍS}

En el ensayo Hacia una arquitectura, publicado por primera vez en París en 1923 y difundido en Brasil por Lucio Costa, Le Corbusier (1964) habla del indispensable diálogo entre arquitectura e ingeniería y dedica varias páginas a describir grandes construcciones utilitarias. Algunas obras de Niemeyer parecen definir el espacio arquitectónico mediante una sencillez monumental que, como sugería Le Corbusier, pone en relación las estructuras funcionales de principios del siglo XX con la magnitud de los antiguos interiores de Roma y Estambul.

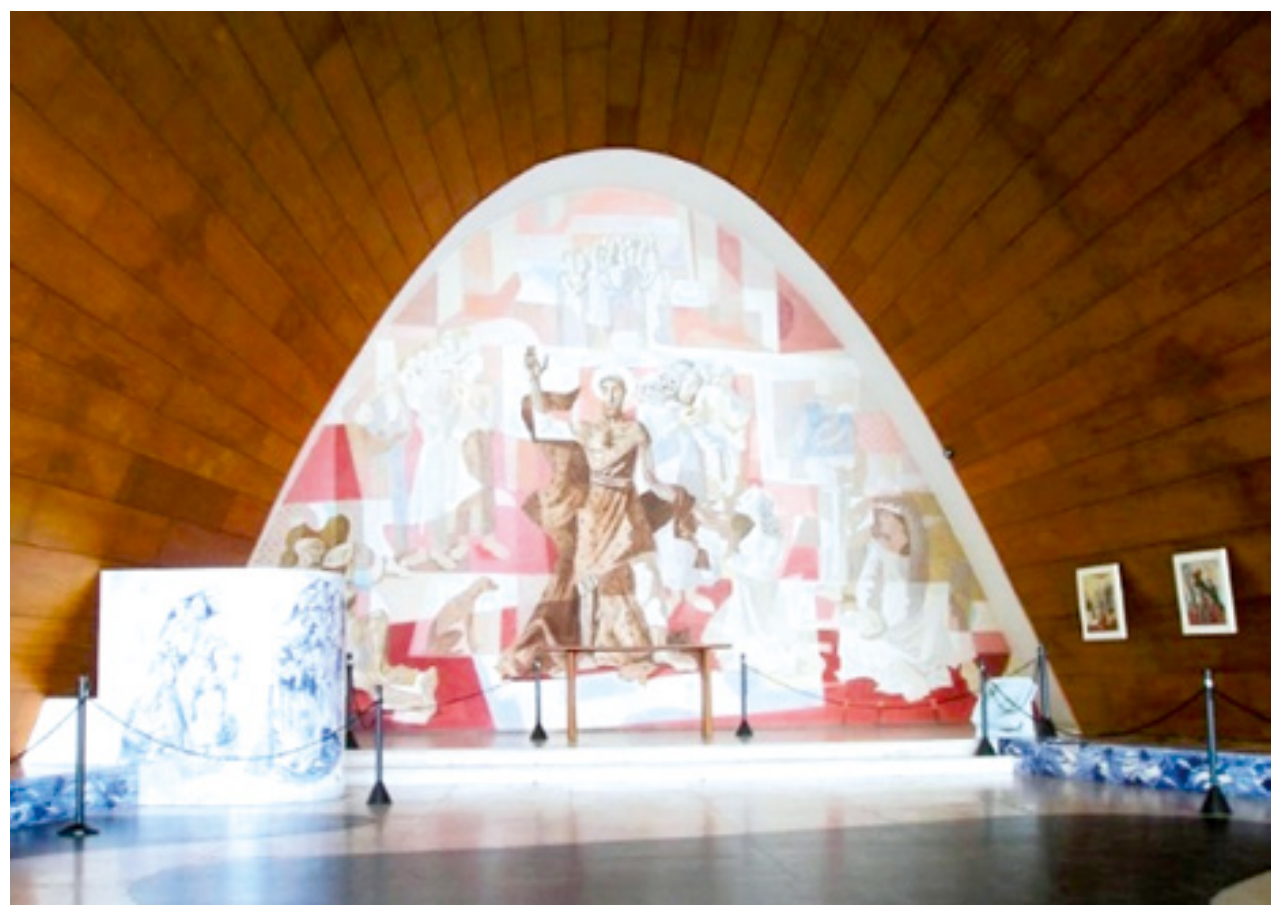

Figura 13. Nave central de la iglesia con el proyecto iconográfico de Candido Portinari. Fuente: fotografía del autor. 
En la Iglesia de San Francisco de Asís, proyectada en 1940, la experimentación en torno a la síntesis técnica-arte-paisaje alcanza un extraordinario valor. Así se aprecia en la fusión de materiales antiguos y modernos, tales como la cerámica esmaltada y el hormigón armado, utilizado para crear el sistema de cáscaras livianas que elimina la habitual dicotomía entre elementos de soporte y aquellos que son soportados. El nexo con el arte sobresale también en los colores y materiales de tradición lusoportuguesa: la madera oscura del intradós de la bóveda principal y los azulejos en la fachada posterior y la piel de las cáscaras. El diseño propone un conjunto de azulejos insertados en una cornisa innovadora, definida gracias a la sensibilidad de Candido Portinari con una sapiente y moderna reinterpretación de la antigua técnica mediterránea de los mosaicos.

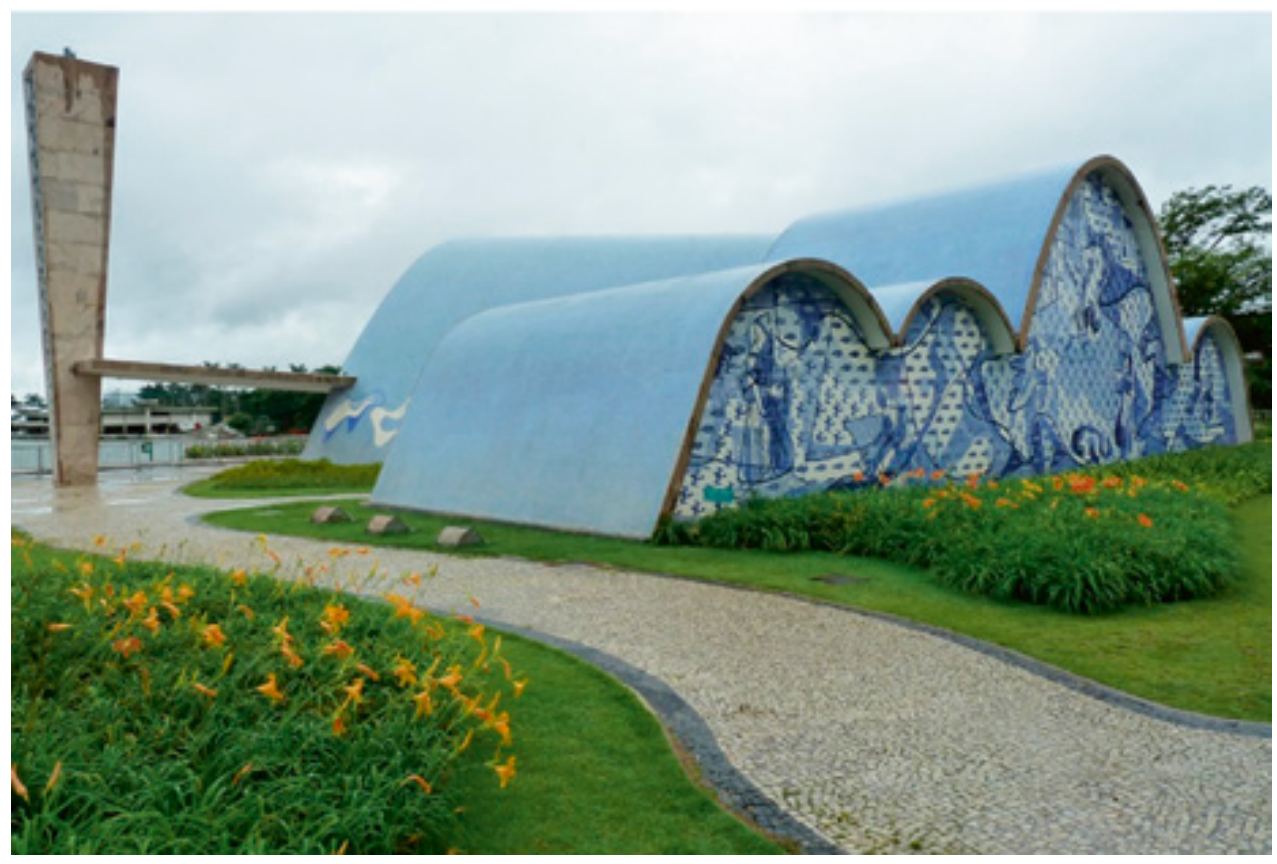

Figura 14. Proyectos iconográficos y paisajísticos de Portinari y Burle Marx en la Iglesia. Fuente: fotografía del autor. 
En cuanto a lo estructural, Joaquim Cardoso resolvió de forma poética una yuxtaposición de bóvedas que rememora conceptualmente el proyecto para la Maison de week-end de Le Corbusier, realizado en 1934.

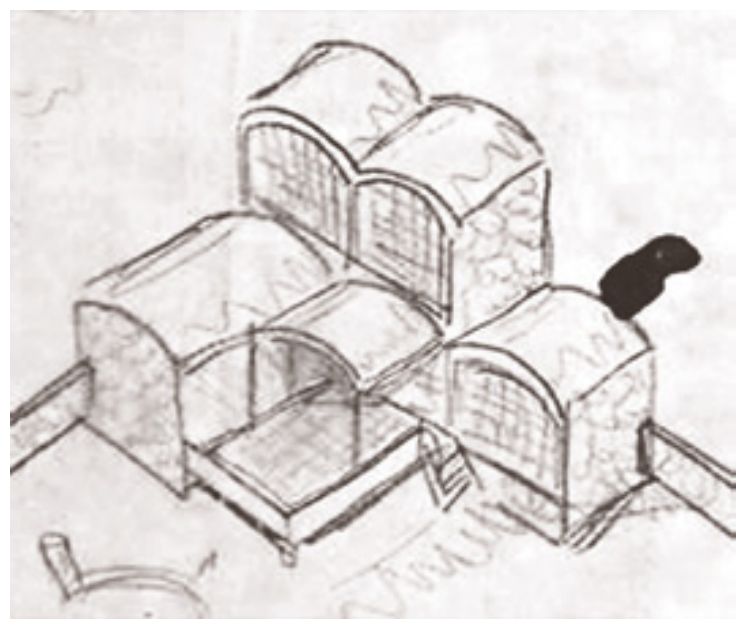

Figura 15. Detalle del croquis de la Maison de week-end en La Celle-Saint-Cloud. Fuente: Fondation Le Corbusier. Disponible en http://www.fondationlecorbusier.fr

La forma de las cáscaras de hormigón parece reinterpretar aquella empleada por el ingeniero Eugène Freyssinet en los hangares del aeropuerto de Orly, en París, en 1916, que el arquitecto carioca conoció gracias a las imágenes publicadas por Le Corbusier en Hacia una Arquitectura. 

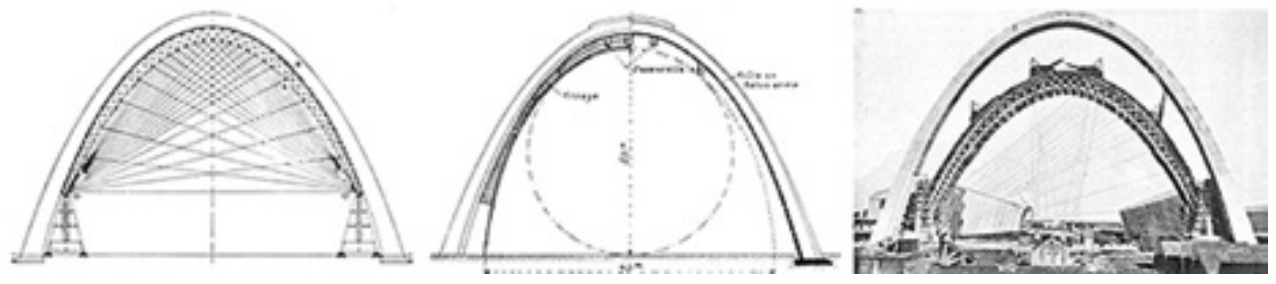

Figura 16. Dibujos y fotografía de la construcción de uno de los hangares del aeropuerto de Orly. Fuente: Urbipedia. Disponible en http://www.urbipedia.org/images/4/42/ Eugene_Freyssinet.Hangares_en_Orly.Planos1.jpg

Una interesante innovación en el tratamiento del sistema de cáscaras es el uso de módulos de dimensiones diferentes: tres pequeños que protegen las áreas más privadas, y uno de gran tamaño que configura la nave central de la iglesia.

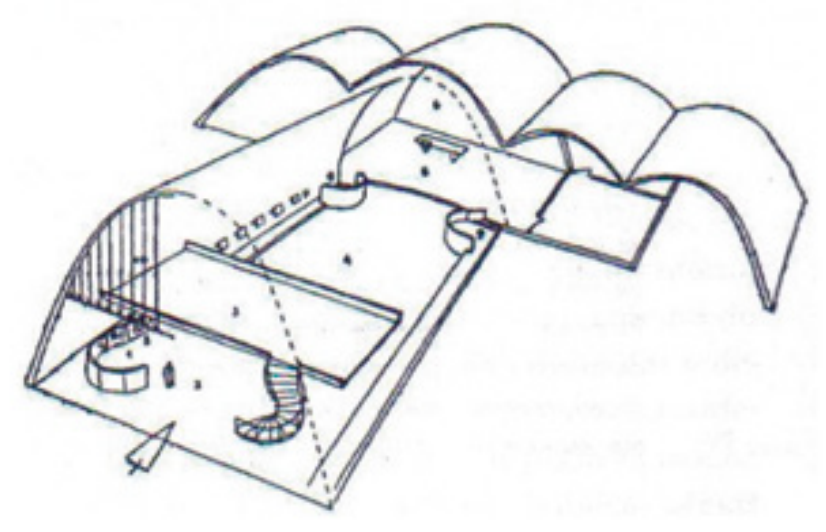


La concatenación de bóvedas parabólicas protagoniza el espacio exterior. El interior es más estático y se logra al ligar las exigencias litúrgicas a la simetría obtenida por medio del eje que conecta el acceso con el altar. La bóveda revestida de láminas de madera oscura que domina la nave central se apoya directamente al suelo. La zona interna se caracteriza por el diálogo entre las curvas del sistema paredes-cubierta, la pared absidal cuya configuración material se disipa gracias al extenso mural de Candido Portinari, y el pavimento dotado de dinamismo a través de las formas sinusoidales desarrolladas conjuntamente con Burle Marx, el cual puede interpretarse como una conexión metafórica con las orillas del lago adyacente.
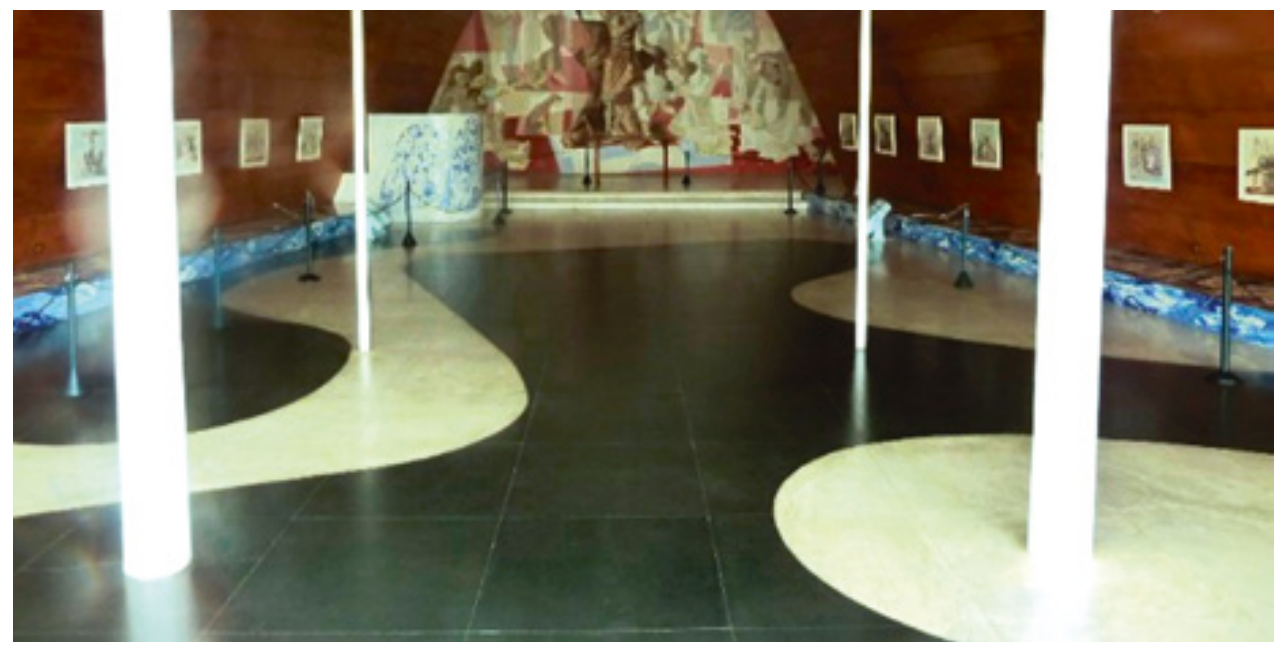

Figura 18. Pavimentación de la nave principal de la iglesia de Pampulha. Fuente: fotografía del autor.

Es inédita la forma como la cubierta de la nave principal se quiebra en la zona del altar. El intersticio entre una cáscara y otra deja un espacio vacío que configura una ventana corrida, en curva, desde la cual penetra la luz que alumbra el área presbiteral y las obras de arte. La bóveda más alta envuelve el presbiterio. 


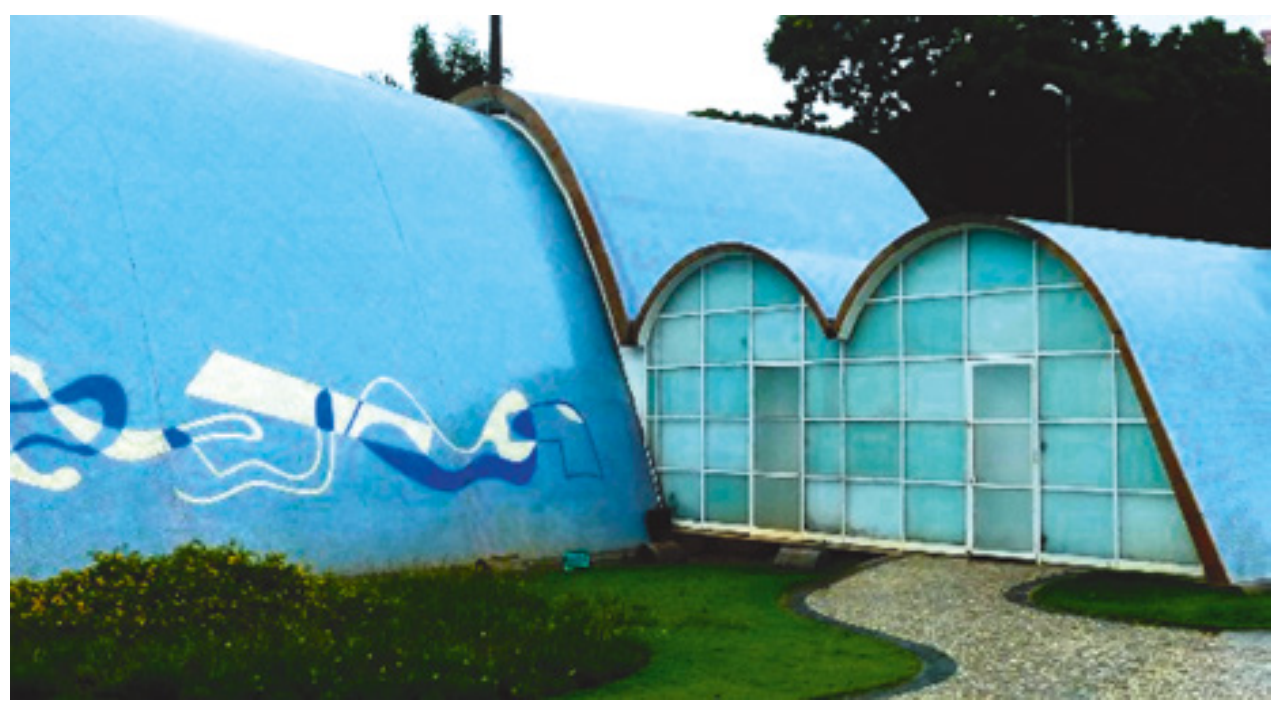

Figura 19. Concatenación entre la nave principal y la zona presbiteral, con el intersticio por el cual penetra la luz natural.

Fuente: fotografía del autor.

Extraordinaria la parte posterior de la iglesia donde la arquitectura actúa como sencilla pantalla para la intervención del pintor. En los materiales y colores, en las texturas y técnicas constructivas se descubre una solución culta y sensible para reinterpretar de forma moderna el arte y la arquitectura de la colonización portuguesa. Esto es así, por ejemplo, en la tonalidad azul, típica de la cerámica decorada esmaltada y de los elementos de madera de construcciones antiguas.

El arquitecto crea un espacio que acoge y abraza: su forma orgánica, su relación con la naturaleza y el arte, la presencia protagónica de los planos curvos de la cubierta que se abre hacia el jardín y el lago para transfigurarse gracias a las obras de arte. La estructura parece perder su consistencia, se desdibuja, los murales de Portinari y de Paulo Werneck saturan la bóveda central y las paredes absidales desde el pavimento hasta la cubierta. El minimalismo arquitectónico resalta las creaciones de los artistas. 
Burle Marx es el autor del proyecto paisajístico que conversa con los murales a través de una grafía de matiz similar: es una sabia concatenación entre pintura y espacio, entre naturaleza y construcción, que da vida a uno de los primeros lugares religiosos de la modernidad donde se funden, como en las antiguas iglesias, las artes con la forma estructural.

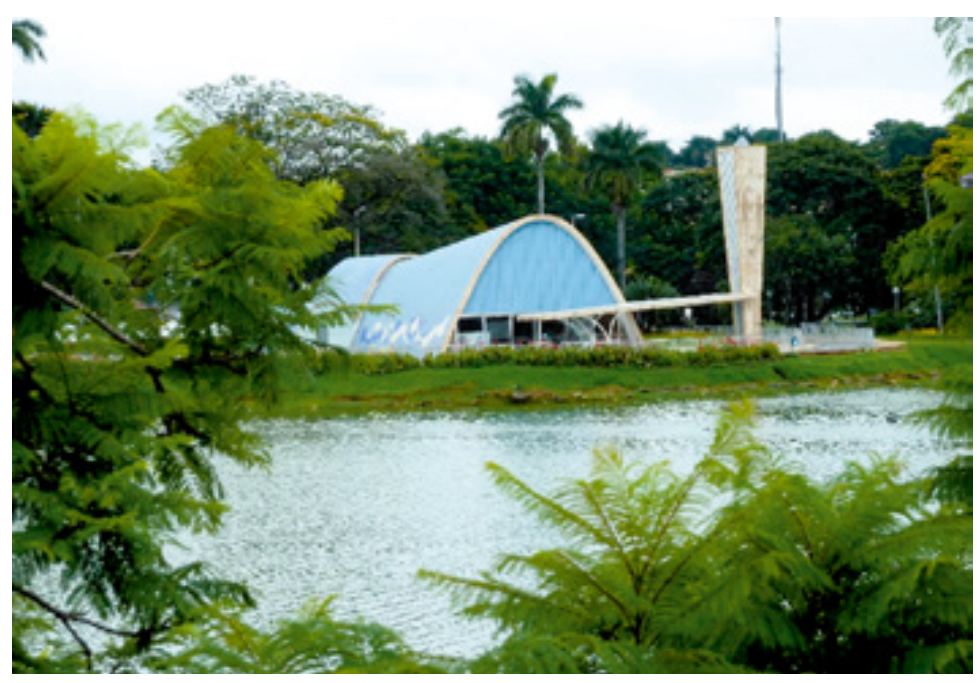

Figura 20. La iglesia de Pampulha y su integración paisajística.

Fuente: fotografía del autor.

\section{COMPARACIONES Y DIÁLOGOS}

Del análisis espacial y plástico de los proyectos emerge con fuerza la idea de componer sinfonías polifónicas en las cuales los elementos artificiales no son protagonistas absolutos sino una parte del conjunto, dispuestos para concatenar paisaje y arquitectura por medio de cánones morfológicos que reinterpretan la geometría de la naturaleza del entorno. Se propone aquí una comparación entre aspectos de las obras y temas básicos de tipo técnico, estructural y paisajístico.

\section{ENSAYOS ESTRUCTURALES}

Los logros de la ingeniería, significativos en la economía estructural, en los espesores mínimos de las cubiertas y en las sensaciones de extrema transparencia y liviandad, no se ostentan en los casos examinados, pero resultan de extraordinaria importancia en la definición espacial. 
En la Casa das Canoas, la técnica es típica del Movimiento Moderno pero la morfología es novedosa. Las columnas metálicas tienden a desaparecer, son esbeltas, de sección mínima y pintadas de negro. Los contornos de la cubierta en hormigón armado se curvan, adquiriendo forma de ameba. En la Casa Canavelas la estructura metálica de la cubierta se genera a través de sencillas cerchas, dejadas a la vista y pintadas de azul, que descansan en los cuatro apoyos perimetrales y en los dos muros neoplásticos. En la iglesia, el sistema de cáscaras livianas en hormigón armado define al mismo tiempo la estructura y los cerramientos. Gracias al integral revestimiento en madera del intradós de la bóveda y a las intervenciones de los artistas, una construcción puramente utilitaria se transfigura en un espacio poético y en comunión con la naturaleza.

\section{COLORES}

Una simbología derivada del mundo acuático caracteriza la iglesia y define varias de las tonalidades y de los temas iconográficos que se emplean en sus obras de arte. El espacio curvo del interior, revestido de madera oscura, podría rememorar el forro de un barco en reposo: el mismo que Le Corbusier reinterpretó como cubierta en la Capilla de Ronchamp (Monteys, 2005). Mármoles de dos colores contrastantes producen el dibujo en forma de ameba en el pavimento, el cual aflora también en el sagrado y se extiende a los recorridos del jardín.

En el salón de la Casa Canavelas se crea un tranquilo nexo entre el pavimento liso en piedra blanca, los muros pétreos y la cubierta revestida con listones de madera. Elementos del mismo tipo forran las dos paredes cóncavas del comedor y del salón de la Casa das Canoas. El piso en este caso es oscuro, en cerámica esmaltada, para reflejar las paredes y el paisaje; los muros externos son verdes, como las copas de los arboles adyacentes; la cubierta es blanca, como una nube.

\section{CONCATENACIÓN ARTE-PAISAJE}

El tema se declina de manera diferenciada en cada caso. En la iglesia, en forma de amplios murales y mosaicos, se pone al servicio de la total transformación poética de una expresión de la ingeniería moderna. En la Casa Canavelas se explicita en el arte del jardín, en tanto en la residencia de Canoas, paredes y cubierta dan vida a formas plásticas que recuerdan las grafías de Pablo Picasso, Hans Arp, Henry Moore, Tarsila do Amaral y Le Corbusier. 
La mujer reclinada, escultura en bronce de Ceschiatti instalada en un lugar adyacente al muro pétreo en la residencia situada en Pedro do Rio, conecta la penumbra de esta con la explosión de colores de los jardines. Es una idealización de las formas del cuerpo humano que parece conversar con la morfología de las colinas. Por su parte, la Casa das Canoas posee una bisagra monumental entre interior y exterior: la escultura natural en forma de piedra. En los recorridos y las estancias al aire libre aparecen puntos estratégicos donde distintas esculturas, también de Ceschiatti, reinterpretan la figura femenina y motivan diálogos visuales entre formas, agua, luz y reflejos. Esta conjugación rememora el juego escultura-agua-luz del patio del Pabellón de Barcelona de Mies Van Der Rohe.

\section{PAISAJES REINTERPRETADOS}

La discrepancia formal de las obras deriva de las especificidades de los lugares para los cuales se concibieron. Los tres entornos presentan características paisajísticas que definen el mundo geográfico y mineral de tres áreas diversas del territorio brasileño: dos en los alrededores de la antigua capital y uno a las afueras de Belo Horizonte. Las residencias están sumergidas en un contexto caracterizado por valles y colinas repletas de vegetación tropical donde el sonido, la brisa, los pájaros y el agua son partes fundamentales del conjunto.

Las montañas circundantes a la Casa das Canoas son de dimensiones enormes y perfiles inusuales que la grafía de la cubierta parece recordar. El entorno de la Casa Canavelas es más abierto, dominado por dos laderas y un conjunto de colinas matizado por una tríplice repetición de mórbidas cumbres de rasgos morfológicos similares: la morada se posiciona en el fondo del valle y la forma orgánica de la cubierta genera un puente visual entre las faldas.

La iglesia no se relaciona con sistemas geológicos montañosos, pues ella misma se configura como un grupo de colinas artificiales en comunión con el vecino lago. Los colores y la morfología del espejo de agua envuelven el proyecto que emerge con protagonismo. La sabia orquestación de la pluralidad de saberes técnicos y artísticos genera en Pampulha un nuevo paisaje que se extiende a lo largo de las orillas a través de una serie de obras modernas que según Kenneth Frampton (2009) representa el ápice de la maestría de Niemeyer. 

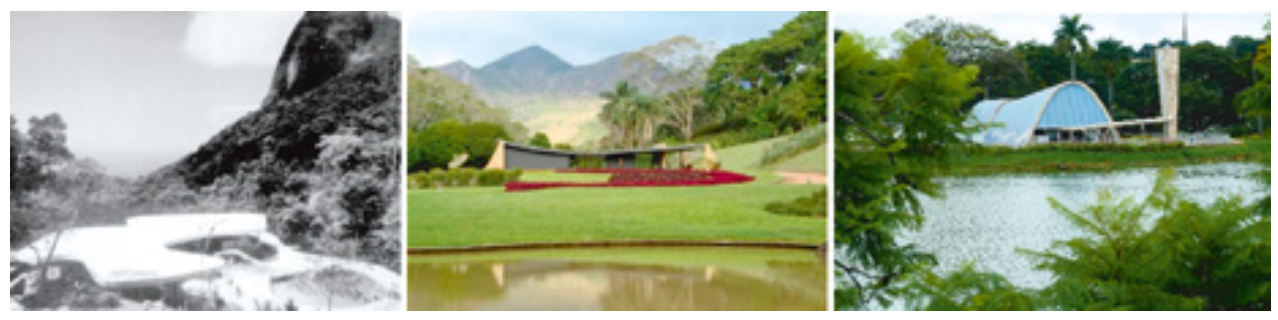

Figura 21. Los tres entornos generan proyectos formalmente diferentes en los cuales las cubiertas tienen un papel protagónico: a. La ameboidal de la Casa das Canoas se relaciona con la montaña adyacente; b. La cóncava de la Casa Canavelas se adapta a las delicadas curvas de las laderas del valle; c. La convexa de la iglesia genera un hito en la horizontalidad del lago. Fuente: Papadaki (1956) (a); fotografías del autor (b, c).

\section{CONCLUSIONES}

Para concluir estas reflexiones, se quiere subrayar que la metodología de trabajo empleada en el proyecto de las tres obras nos trasmite enseñanzas de notable congruencia, las cuales pueden ser de gran utilidad para el desarrollo de nuevas propuestas paisajísticas contemporáneas en relación armónica con el mundo natural, climático y plástico de las áreas tropicales. Se resumen aquí cuatro premisas básicas de esta metodología.

a. El diálogo constructivo. El arquitecto actúa como un director de orquestra que facilita una sapiente combinación entre formas, espacios y artes. La colaboración multidisciplinaria ha sido la base de la estrategia de acción en los más interesantes proyectos del Moderno de Brasil: intelectuales, poetas, artistas y paisajistas han dado vida a una dinámica colaborativa que ha permeado este método proyectual dialógico e inclusivo. 
b. La correspondencia en las reglas morfológicas de la arquitectura con el entorno. Los mismos principios formales que se encuentran en los perfiles de las montañas, las colinas, las orillas del territorio del país, aparecen en los trazos de la arquitectura, los jardines y las obras de arte que se han analizado.

c. Las morfologías dicotómicas. Se experimenta la convivencia de dos tipos de geometría: la platónica de los "volúmenes puros" y la orgánica de los elementos biológicos y geológicos. Así, un conjunto de grafías tropicales reinterpreta el juego de las rectas de los referentes europeos y la arquitectura colonial, junto a las curvas de las formas naturales y minerales brasileñas.

d. La parsimonia. Tema esencial para lograr la sabia integración entre lo natural y lo artificial es la frugalidad y la precisión de las ideas puestas en juego. Un proceso de purificación abraza estos conjuntos armónicos y permite descartar conceptos, colores y materiales innecesarios. Ahorrar ideas significa ahorrar material. En las obras examinadas la parsimonia parece ser un precepto primordial: clarifica nociones, hace posible la sencillez, economía y pureza, favorece la incorporación, facilita la combinación entre saberes diferentes y evidencia la sensibilidad plástica de los artistas.

La búsqueda paciente del Movimiento Moderno de Brasil se presenta entonces como revolucionaria por la fusión de diversos aspectos del mundo de las artes y las técnicas. Gracias a la reinterpretación de cánones morfológicos del paisaje autóctono se desarrollaron novedosas grafías, surgidas del trabajo proyectual de grupos multidisciplinarios que incorporaron los saberes de audaces ingenieros y maestros pintores, muralistas y escultores. Se alcanzó así, a partir de los años cuarenta, una sabia estrategia de intervención que proporcionó, por ejemplo, las herramientas para la construcción de Brasilia y que -como afirma Frampton (2009)influenció a los más abiertos arquitectos, artistas y paisajistas, fuera y dentro del continente americano. 


\section{REFERENCIAS BIBLIOGRÁFICAS}

Aalto, A. (2000). La Casa de Oscar Niemeyer en las afueras de Río de Janeiro. En G. Schildt (ed.). Alvar Aalto. De palabra y por escrito (p.198). Madrid: El Croquis.

Abalos, I.(2009). Os rabiscos de Niemeyer. En R. Segre (ed.). Tributo a Niemeyer (pp. 56-61). Rio de Janeiro: Viana.

Bohigas, O. (2012, junio 12). Ética y política de la arquitectura. El País. Recuperado el 10 de mayo de 2014, de http://cultura.elpais.com/cultura/2012/12/06/actualidad/1354824125_469043.html

Curtis, W. (2012, junio 12). Constructor de un mundo pasado. El País. Recuperado el 10 de mayo de 2014, de http://cultura.elpais.com/cultura/2012/12/06/actualidad/1354824749_719681.html

Frampton, K. (2009). Homenagem a Niemeyer. En R. Segre (ed.). Tributo a Niemeyer (pp. 26-27). Rio de Janeiro: Viana.

Le Corbusier. (1995). Le Corbusier. OEuvre Complete, 1910-1969, volumen IV. Basilea, Suiza: Birkhäuser Verlag.

Le Corbusier. (1964). Hacia una arquitectura. Buenos Aires: Poseidón.

Monteys, X. (2005). Le Corbusier, obras y proyectos. Barcelona: Gustavo Gili.

Niemeyer, O. (1998). As Curvas do Tempo. Rio de Janeiro: Revan.

Papadaki, S. (1956). Oscar Niemeyer, Works in progress. New York: Reinhold Publishing Corporation.

Petit, J. (2014). Testi e disegni per Ronchamp. Regensburg, Alemania: Verlag.

Sartoris, A. (2005). Oscar Niemeyer o la arquitectura concentrada y emblemática. En Botey, J., Oscar Niemeyer. Obras y proyectos (pp. 9-13). Barcelona: Gustavo Gili.

Siqueira, B. (2001). Burle Marx. São Paulo: Cosac e Naify.

Underwood, D. (2010). Oscar Niemeyer e o modernismo de formas livres no Brasil. Sao Paulo: Cosac Naify.

Zevi, B. (1997). Storia e controstoria dell'architettura. Roma, Italia. Newton.

Zevi, B. (1982). Storia dell'architettura moderna. Bologna, Italia: Zanichelli. 